\title{
Minimaal-invasieve technieken bij benigne prostaathyperplasie
}

\author{
Xiaoye Zhu • Frank C. H. d'Ancona
}

\section{Introductie}

De TURP (transurethrale resectie van de prostaat) is nog steeds de gouden standaard bij chirurgische desobstructie bij benigne prostaathyperplasie (BPH). Toch zijn er significante risico's aan de operatie verbonden, zoals nabloeding, blaashalssclerose, urethrastrictuur en seksuele disfunctie, ondanks de intrede van bipolaire en vaporiserende technieken. Er zijn dan ook meerdere ontwikkelingen binnen de minimaal-invasieve urologie die zich richten op het verminderen van de kans op complicaties en seksuele bijwerkingen, maar die net zo effectief pogen te zijn als de TURP.

Lasertechnieken die gebruikmaken van holmium, thulium en greenlight zijn langer bestaande alternatieven voor de TURP, waarvan met name de enucleatietechnieken veelbelovend zijn. Echter, door de beperkte beschikbaarheid, relatief lange leercurve en de soms tegenstrijdige resultaten die in de literatuur worden beschreven, hebben deze technieken de TURP nog niet verdrongen, iets wat wellicht nooit zal gebeuren.

In dit artikel zullen we ons focussen op de minimaal-invasieve technieken die de revue passeerden op de EAU20 Virtual.

\section{Minimaal-invasieve technieken}

\section{Aquablation}

Aquablation is een concept dat bestaat uit echoplanning met nadien het robotgeassisteerd transurethraal ableren van de prostaat met een hogedruk waterstraal (fig. 1 [1]). In postersessie 3 werden de tweejaarsdata van de Waterjet Ablation Therapy for Endoscopic Resection of Prostate Tissue (WATER)-studie gepresenteerd (tab. 1) [2]. In deze multicenterstudie werden 181 patiënten met een prostaat tot $80 \mathrm{cc}$ gerandomiseerd naar aquablation of TURP. Functionele uitkomsten (zoals de Internationale Prostaat Symptoom Score (IPSS), de maximale flow $\left(\mathrm{Q}_{\max }\right)$ en het

dr. X. Zhu $(\bowtie) \cdot$ dr. F. C.H. d'Ancona

afdeling Urologie, Radboudumc, Nijmegen, Nederland xiaoye.zhu@radboudumc.nl

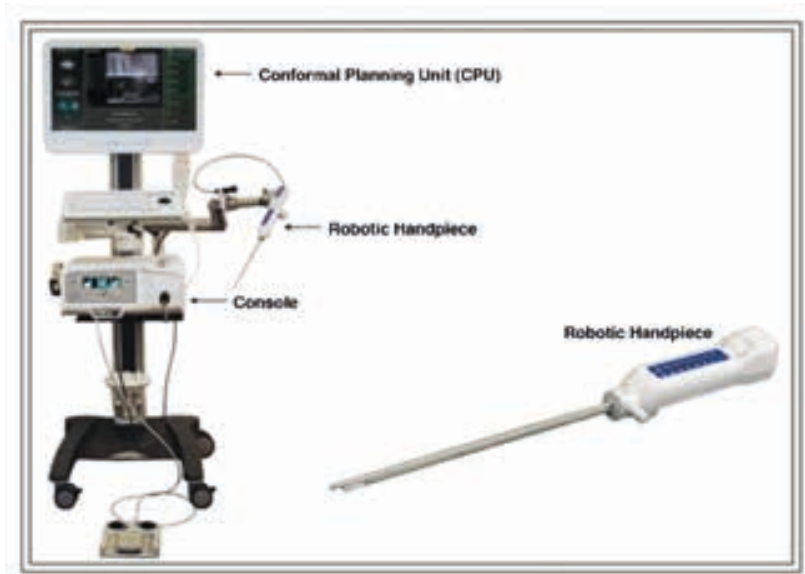

Figuur1 Aquablation(https://www.procept-biorobotics.com/ aquabeam-surgical-robotic-system/\#section-aquablationprocedure). Bron: [1]

residu na mictie) bleken tussen beide groepen vergelijkbaar. Aquablation ging gepaard met minder (seksuele) bijwerkingen. Het verschil in re-interventie ten gunste van TURP tussen beide groepen was echter niet statistisch-significant.

In dezelfde postersessie werden de resultaten van de WATER II-studie gepresenteerd. In die studie waren 101 mannen geïncludeerd met een prostaat van 80-150 cc, waarvan $72 \%$ met een middenkwab. De IPSS daalde van 23 naar 5 en de $Q_{\max }$ verbeterde van 8,7 naar 16,6 ml/s. Na twee jaar vond bij $1 \%$ van de patiënten re-interventie plaats. De complicatiekans was laag, al was deze kans niet uitgesplitst naar event [3].

De meest gehoorde kritiek op aquablation behelst de relatief hoge kans op nabloeding (ca. 10\%). In de eerdergenoemde WATER-studie werd hemostase bereikt door coagulatie of door een katheter in de urethra prostatica achter te laten. In de WATER II-studie werd een op tractie gebrachte katheter achtergelaten in de blaas of urethra prostatica, met 40-80 cc water in de ballon. Een retrospectieve studie uit Beirut laat zien dat het nacoaguleren geen toegevoegde waarde heeft boven het achterlaten van een katheter op tractie [4]. 


\begin{tabular}{|c|c|c|c|c|c|}
\hline Techniek & Aquablation & Rezum & Urolift & iTind & PAE \\
\hline principe & $\begin{array}{l}\text { robotgeassisteerd } \\
\text { ableren prostaat door } \\
\text { waterstraal }\end{array}$ & $\begin{array}{l}\text { thermisch } \\
\text { (stoominjecties) }\end{array}$ & $\begin{array}{l}\text { mechanisch (ankers in } \\
\text { prostaatkwabben) }\end{array}$ & $\begin{array}{l}\text { tijdelijk implantaat dat } \\
\text { de urethra prostatica } \\
\text { incideert, met remodel- } \\
\text { ling als gevolg }\end{array}$ & $\begin{array}{l}\text { emboliseren prostaat- } \\
\text { arteriën }\end{array}$ \\
\hline setting & $\begin{array}{l}\text { algehele anesthesie, } \\
\text { klinisch }\end{array}$ & $\begin{array}{l}\text { lokale anesthesie, } \\
\text { dagbehandeling }\end{array}$ & $\begin{array}{l}\text { lokale anesthesie en/of } \\
\text { sedatie, dagbehandeling }\end{array}$ & $\begin{array}{l}\text { (lichte) sedatie, } \\
\text { dagbehandeling }\end{array}$ & $\begin{array}{l}\text { lokale anesthesie, } \\
\text { dagbehandeling }\end{array}$ \\
\hline antistolling & eventueel ascal & staken? & staken & staken? & geen beperking \\
\hline prostaatgrootte & tot $80-150 \mathrm{cc}$ & tot $80 \mathrm{cc}$ & tot $70-100 \mathrm{cc}$ & tot $60 \mathrm{cc}$ & geen limiet \\
\hline best evidence & $\begin{array}{l}1 \text { RCT, } 2 \text { prospectieve } \\
\text { studies }\end{array}$ & $\begin{array}{l}1 \mathrm{RCT}, 1 \text { prospectief } \\
\text { cohort }\end{array}$ & $\begin{array}{l}\text { RCT's (data hieronder uit } \\
\text { L.I.F.T.-studie) }\end{array}$ & 2 prospectieve studies & 5 RCT's \\
\hline follow-up & $\max .2$ jaar & max. 4 jaar & max. 5 jaar & 3 jaar & max. 2 jaar \\
\hline IPSS-verlaging & 13 punten & $48 \%$ & $41 \%$ & $19 \%$ & 9-17 punten \\
\hline$Q_{\max }$-verbetering & $96 \%$ & $49 \%$ & $49,9 \%$ & $41 \%$ & $3,1-14,2 \mathrm{ml} / \mathrm{s}$ \\
\hline erectiele disfunctie & $0 \%$ & $0 \%$ & $0 \%$ & $?$ & IIEF: $-2,56$ \\
\hline retrograde ejaculatie & $0,8 \%$ & tot $6 \%$ & $0 \%$ & $0 \%$ & tot $56 \%$ \\
\hline re-interventie & $4,3 \%$ & $4,4 \%$ & $13,6 \%$ & $0 \% ?$ & $9,45 \%$ \\
\hline
\end{tabular}

IIEF International Index of Erectile Function, IPSS International Prostate Symptom Score, iTind i-temporary implantable nitinol device, L.I.F.T. Luminal Improvement Following Prostatic Tissue Approximation for the Treatment of LUTS secondary to BPH, PAE prostatic artery embolization, $\mathrm{Q}_{\max }$ maximale flow, $R C T$ randomised controlled trial.

\section{Rezum}

Rezum (fig. 2) is een techniek waarbij transurethraal stoominjecties $\left(103^{\circ} \mathrm{C}\right)$ worden toegediend. Door convectie van radiofrequente stoom via het interstitium van de transitiezone wordt apoptose geïnduceerd en daarmee desobstructie bewerkstelligd. De injecties worden $1 \mathrm{~cm}$ van elkaar geplaatst en 1 injectie duurt 9 seconden. De resorptietijd is 1-3 maanden. De vijfjaarsdata werden gepresenteerd tijdens plenaire sessie 4 (tab. 1). De verbetering in functionele uitkomsten waren de vijf jaar volgend op de ingreep consistent.

Tijdens dezelfde sessie werden ook Britse eenjaarsdata getoond van een studie naar rezum, waarin de IPSS daalde van 20 naar 5; de score voor de kwaliteit van leven verbeterde van 4 naar 1 . De erectiele functie bleef onveranderd en bij $3 \%$ van de patiënten was sprake van retrograde

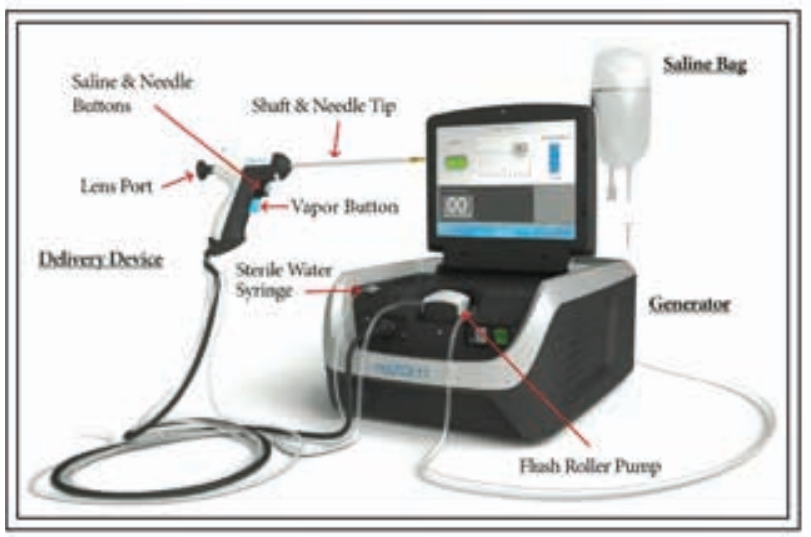

Figuur 2 Rezum (https://www.bostonscientific.com/en-US/ products/lithotripsy/rezum-water-vapor-therapy/healthcareprofessionals-resources.html). Bron: Boston Scientific ejaculatie. De gemiddelde opnameduur was negen uur en het gemiddelde katheterverblijf zes dagen.

\section{Urolift}

De urolift (fig. 3) is een minimaal-invasieve techniek die al langere tijd bekend is in de urologie. Vooralsnog is een urolift volgens de EAU-richtlijn geïndiceerd bij patiënten met een prostaat tot $70 \mathrm{ml}$ zonder obstructieve middenkwab, die een sterke wens hebben om hun ejaculatie te behouden. Tijdens plenaire sessie 4 werden de vijfjaarsdata getoond van de L.I.F.T. (Luminal Improvement Following Prostatic Tissue Approximation for the Treatment of LUTS secondary to BPH) studie. De IPSS-daling en de verbetering van de $\mathrm{Q}_{\max }$ bleven 4-5 jaar na plaatsing consistent. De re-interventiekans na vijf jaar was $13,6 \%$ $(9,4 \%$ onderging TURP of greenlight laser en $4,3 \%$ opnieuw urolift).

Interessant is de PULSAR (Prostatic Urethral Lift in Subjects with Acute Urinary Retention) studie waarin 52 patiënten werden onderzocht, die gemiddeld 132,4 dagen een katheter in situ hadden, en bij wie minstens een keer de trial-without-catheter was mislukt [5]. Gemiddeld werden per patiënt 4,8 implantaten geplaatst. $58 \%$ had een succesvolle trial-without-catheter op dag 3; 60 en $73 \%$ van de patiënten waren kathetervrij na een periode van 1 en 12 maanden. De daling op de IPSS was vergelijkbaar met die in de L.I.F.T- en de BPH6-studie (40-50\%). Re-interventie vond plaats bij acht patiënten, van wie er zes chirurgische desobstructie ondergingen en twee opnieuw urolift. Urodynamische verbeteringen betroffen een lagere $\mathrm{pdet}_{\max }$ (detrusordruk bij maximale flow) bij $22 \%$ van de patiënten en een lagere score op de bladder outlet obstruction index (BOOI) bij 38\% van de patiënten. 


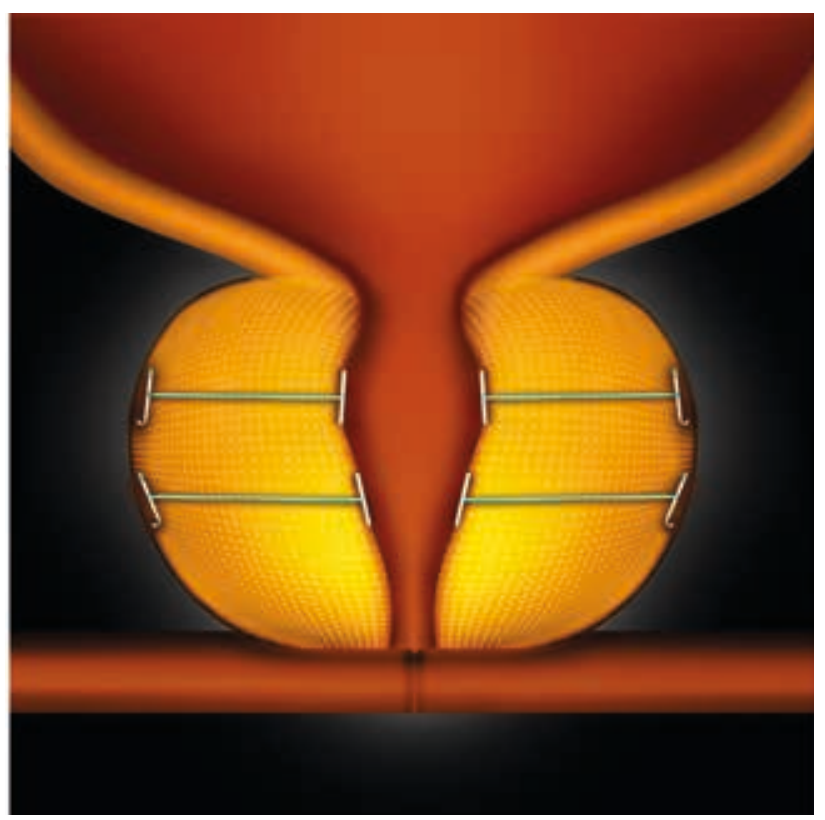

Figuur 3 Urolift (https://www.urolift.com/physicians/procedure-device). Bron: Teleflex

\section{iTind}

iTind (i-Temporary Implantable Nitinol Device) (fig. 4) is een tijdelijk implantaat, dat bestaat uit drie nitinoldraden die na cystoscopische plaatsing op 5, 7 en 12 uur de urethra prostatica insnijden. Na vijf tot zeven dagen wordt het implantaat verwijderd via een nylondraad die aan het implantaat vastzit. Door middel van reshaping en remodeling wordt vervolgens desobstructie bereikt.

Eén studie rapporteerde dat na zes maanden iTind de IPSS was gedaald van 25 naar 10 en de $Q_{\max }$ was verbeterd van 7,34 naar 12,08 ml/s [6]. Als bijwerkingen werden in deze studie onder andere passagère hematurie (39\%), irritatie $(52 \%)$, incontinentie ten tijde van de iTind $(8,5 \%)$ en postoperatieve pijn (NRS 3-4) beschreven.

De driejaarsresultaten van iTind werden samengevat tijdens plenaire sessie 4 . In een studie met 32 mannen zette na drie weken een daling op de IPSS in, die zich verder doorzette naar een daling van $19 \%$ na drie jaar. Daarnaast verbeterde de $Q_{\max }$ met $72 \%$ na zes weken en $41 \%$ na drie jaar. Vier patiënten kregen te maken met een complicatie (prostaatabces, urineretentie, passagère incontinentie door migratie van de iTind en urineweginfectie). Van de 19 patiënten die seksueel actief waren, rapporteerde niemand retrograde ejaculatie.

\section{Prostaatembolisatie (PAE)}

PAE is een radiologische interventie (https://www.youtube.com/watch?v=8IO86t1Eeac) die is gereserveerd voor een selecte groep patiënten met bijvoorbeeld een harde indicatie voor (dubbele) antistolling, of patiënten die niet geschikt zijn voor anesthesie.

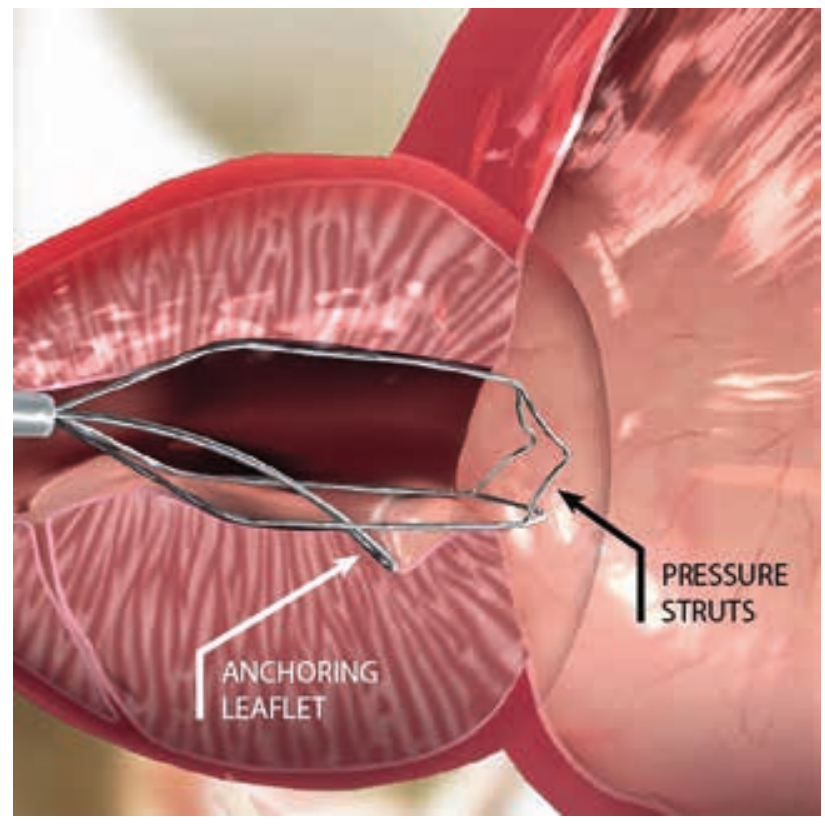

Figuur 4 iTind (https://www.itind.com/physicians-procedure/). Bron: Medi-Tate

In plenaire sessie 4 werden tweejaarsdata gepresenteerd van een RCT naar PAE die werd uitgevoerd in Zwitserland. De verlaging op de IPSS was goed vergelijkbaar met die van een TURP. De $\mathrm{Q}_{\max }$ en het residu na mictie waren echter duidelijk in het voordeel van TURP, evenals de urodynamische bevindingen. De kans op re-interventie na PAE bleek $9,45 \%$ (uitkomst RCT) na 2 jaar en $23,7 \%$ na 4-6,5 jaar (uitkomst retrospectieve studies).

De kracht van PAE is het lage risico op (ernstige) bijwerkingen. Bovendien is de kans groot (> 85\%) dat de (kwetsbare) patiënt van een verblijfskatheter af komt. PAE is onder de interventieradiologen (in Nederland) echter nog geen wijdverspreide techniek.

\section{De toekomst}

Alle hiervoor beschreven methoden, mogelijk met uitzondering van aquablation wat betreft nabloeding, hebben een gunstiger veiligheidsprofiel dan TURP, wat ook het streven is van een minimaal-invasieve techniek. De ervaring met deze methoden is echter nog beperkt, terwijl follow-up uit een RCT maximaal vijf jaar bedraagt. Functionele uitkomsten op de lange termijn zijn daarom nog niet te vergelijken met die van de TURP.

Er is een (landelijk) netwerk nodig, waarin urologen onderling van elkaar weten wie wat doet. Idealiter is het dan mogelijk om een RCT op te zetten, waarin de uitkomsten van meerdere technieken tegen elkaar worden uitgezet. Op basis van die data kan dan vervolgens een keuzehulp ontwikkeld worden met als doel patiënten beter te kunnen counselen en een behandeling op maat te kunnen aanbieden, ook al zou die in een ander ziekenhuis worden uitgevoerd. 
Open Access This article is distributed under the terms of the Creative Commons Attribution 4.0 International License (http:// creativecommons.org/licenses/by/4.0/), which permits unrestricted use, distribution, and reproduction in any medium, provided you give appropriate credit to the original author(s) and the source, provide a link to the Creative Commons license, and indicate if changes were made.

\section{Literatuur}

1. Yassaie O, Silverman JA, Gilling PJ. Aquablation of the prostate for symptomatic benign prostatic hyperplasia: early results. Curr Urol Rep. 2017;18;91

2. Barber N, Gilling P, Bidair M, et al. Two-year outcomes after aquablation compared to TURP: Results from a blinded randomized trial. EAU20 Virtual, abstract 201.

3. Zorn K, Bidair M, Trainer A, et al. Aquablation for benign prostatic hyperplasia in large prostates (80-150 cc): 2-year results. EAU20 Virtual, abstract 202.
4. Labban M, Abdallah N, Wazzan W, Bulbul M, El Hajj A. The role of cautery in aquablation for benign prostatic obstruction: Is it imperative? A single tertiary center experience. EAU20 Virtual, abstract 205.

5. Rochester M, Page T, Barber N, Thiruchelvam N, Kavia R, Kayes O. 12 month symptom and urodynamic outcomes of the prostatic urethral lift in patients with acute urinary retention (PULSAR). EAU20 Virtual, abstract 214.

6. de Nunzio C, Cantiello F, Fiori C, et al. Functional, urinary and sexual outcomes after treatment with Temporary implantable nitinol device (iTind) in men with LUTS: 6 months interim results of the MT-06-study. EAU20 Virtual, abstract, poster, presentation 206.

dr. Xiaoye Zhu uroloog

dr. Frank C. H. d'Ancona uroloog 